\section{Luz Rodríguez}

Carranza *

Universidad de Santa Catarina, Brasil -

Universidad de

Leiden, Holanda

\section{La lechuza de Minerva. Realismo y catástrofe}

\author{
Minerva's Owl. Realism and Catastrophe
}

El hilo de la fábula Universidad Nacional del Litoral, Argentina ISSN-e: 2362-5651

Periodicidad semestral, julio-diciembre, 2021 vol. 19, núm. 22, e0006, revistaelhilodelafabula@ fhuc.unl.edu.ar

Recepción: 14082021 Aprobación: 16092021

URL: http://portal. amelica.org/ameli/ jatsRepo/247/2472702003/ index.html DOI: https://doi. org/10.14409/hf.19.22. e0006

Esta obra está bajo una Licencia Creative Commons Atribución-NoComercialCompartirlgual 4.0 Internacional.

\section{Resumen}

El pensamiento, como el ave de Minerva, inicia su vuelo al atardecer. Para Hegel eso era prueba de sabiduría, hoy solo indica un fracaso: los hechos le explotan en la cara. La filosofía y la crítica, con pocas excepciones, sostienen aún que solo hay «ficciones consensuales» (Rancière 2008) o, como denuncia Alain Badiou, que «no hay más que cuerpos y lenguajes» (Badiou 2008:621). La ciencia y el arte, en cambio, han imaginado la catástrofe con soltura desde hace siglos, y un realismo que recupere la tensión ética en el sentido del cambio (Gramuglio) será el que piense y señale la vacilación de las ficciones hacia lo real. En Pongamos por caso (2020), obra estructurada por Rafael Spregelburd y acribillada por performances delegadas de traductores, el dramaturgo «hace cómplice al espectador de que está frente a una actuación, pese a que esta esté atravesada por estados de verdad. Y que eso es lo real». (Spregelburd 2010:170-171)

\section{Palabras clave}

realismo, catástrofe, performance delegada, ficción, Rafael Spregelburd.

\section{Abstract}

Thinking, like Minerva's owl, spreads its wings only with the falling of dusk. Whereas for Hegel, this was a proof of wisdom, now it only indicates failure: facts explode in his face. Philosophy and criticism, with a few exceptions, still argue that there are only «consensual fictions» (Rancière 2008) or, as Alain Badiou denounces, that «there are only bodies and languages» (Badiou 2008:621). Psychoanalysis, science and art, instead, have been able to imagine catastrophe with ease for a long time, and a kind of realism capable of recovering the ethical tension in the sense of change (Gramuglio) will be the one that thinks and signals the hesitation of fictions towards the real. In Pongamos por caso (2020), structured by Rafael Spregelburd and riddled by delegated performances of translators, the playwright «makes an accomplice out of the spectator of the fact that he is witnessing an act, despite it being traversed by states of truth. And that is what is real» (Spregelburd 2010:170-171).

\section{Keywords}

realism, catastrophe, delegated performance, fiction, Rafael Spregelburd.

\footnotetext{
* Luz Rodríguez Carranza es doctora por la Universidad de Lovaina (K.U.Leuven, Bélgica). Es profesora visitante en la Universidad Federal de Santa Catarina (Brasil) y catedrática emérita en la Universidad de Leiden (Países Bajos). Libros: Un Teatro de la Memoria (1991), Interpelaciones (2019) y, en colaboración, Literatura y Poder (1995), Reescrituras (2004), Imágenes y Realismos en América Latina (2014) y Lazos (2019).
} 
Las genealogías de la discusión sobre el realismo en la crítica artística y literaria argentinas de lo que va del siglo XXI pueden verse reflejadas en varios artículos de María Teresa Gramuglio (Gramuglio, 2002a; 2002b) y en las jornadas sobre el tema en Rosario en 2005, organizadas por Analía Capdevila y Sandra Contreras. ${ }^{1}$ Hoy es nuevamente Contreras (2018) quien señala el punto de inflexión entre aquellas discusiones y las que siguieron sobre la «pulsión de lo real» (Foster, 2001 [1996]), el «arte fuera de sí» (Escobar, 2004) la «narrativa del presente» (Contreras, 2007), los «espectáculos de realidad» (Laddaga, 2007) y la «postautonomía» (Ludmer, 2010), por solo nombrar algunas. El foco es la exigencia de compromiso político de la crítica que acompañó siempre esas discusiones, o, citando a Gramuglio, «la tarea de recuperar la tensión ética» (...) para transformarla en «las condiciones del presente, en el sentido del cambio históricamente necesario.» (Contreras, 2018:9). ${ }^{2}$

Me interesa - y me interesó (autor, 2016) - destacar con Contreras que lo que regresa en las discusiones es una doxa que da por sentado que el arte y la realidad son dos campos distintos y que el primero debe dejar el suyo para entrar en el otro, ampliarse para incluirlo, o incluirse en él, lo que Rancière denomina la «ficción consensual»:

No hay tal cosa como un mundo real que vendría a ser el afuera del arte. Hay pliegues y repliegues del tejido sensible común donde se unen y se separan la política de la estética y la estética de la política. No existe lo real en sí, sino configuraciones de aquello que es dado como nuestro real, como el objeto de nuestras percepciones, de nuestros pensamientos y de nuestras intervenciones. Lo real es siempre fruto de una ficción, es decir, de una construcción del espacio donde se anudan lo visible, lo decible y lo factible. Es la ficción dominante, la ficción consensual la que niega su carácter de ficción haciéndose pasar por lo real en sí, trazando una línea divisoria simple entre el dominio de ese real y el de las representaciones y las apariencias, de las opiniones y de las utopías. ${ }^{3}$ (Rancière, 2008: 83-84)

Contreras señala que la denuncia de Rancière no concierne a la crisis del arte, sino al contexto de los discursos críticos que la decretan o, dicho en otros términos, la «metamorfosis posmoderna del pensamiento crítico en pensamiento del duelo» (Contreras, 2018:10). Hay una coincidencia entre la «ficción consensual» y el «discurso de la finitud», que sostiene que «solo hay cuerpos y lenguajes», según Alain Badiou, quien modifica sin embargo el axioma con una torsión gramatical: «solo hay cuerpos y lenguajes. Pero también hay verdades» (Badiou, 2008 [2006]:20). Dicho de otro modo, hay algo que no son los cuerpos ni es producido por las ficciones consensuales. Es el mismo Rancière quien lo señala, es el disenso: el cambio, la aparición de lo incontado, la política, porque «hay política cuando hay un lugar y unas formas para el encuentro entre dos procesos heterogéneos» (Rancière, 1996 [1995]). Cuando esa ruptura deja huella, y marca el espacio abierto en la fidelidad de un nombre, impidiéndole cerrarse, es acontecimiento (Badiou, 2008 [2006]: 396-438). Contreras sugiere «leer la pulsión contemporánea por lo real con discursos de otros ángulos» (Contreras, 2018:25), y esa propuesta es, a mi juicio, la manera en que la crítica puede facilitar el encuentro entre procesos heterogéneos: lo político.

\section{La lechuza de Minerva}

Gramuglio fue muy clara cuando relacionó la necesidad de recuperar la tensión ética del realismo en el sentido del cambio necesario. Es a eso, precisamente, a lo que aluden Rancière, cuando deplora la interpretación errada que hace Lyotard de lo sublime kantiano, y Ferraris cuando ataca «la desublimación de la derecha deseante y reaccionaria, del llamado 
al cuerpo y sus grandes razones» (Ferraris, 2012:5). También para Alain Badiou el hombre es víctima en la ética contemporánea que solo lo considera un ser para la muerte, aplicando una ideología hegemónica, la de la vida, demasiado corta para dejarse llevar por cualquier proyecto ilusorio, que de todos modos fracasa. El único imperativo es la culpabilización vitalista, que no tiene ni fuerza conceptual ni moviliza (Badiou, 2004 [2003]). Lo sublime kantiano no es, sin embargo, un universal, como lo interpreta Lyotard, sino la dimensión de lo imposible reivindicada por Lacan, vale decir, de lo real, que no es transitivo - no tiene objeto - ni consensual, ni obedece a regla o superyo ninguno (Rodríguez Carranza, 2019). Es lo suplementario, que aparece en un acto totalmente imprevisto, un efecto que parece anteceder a las causas.

Ahora bien, como afirma Hegel, la lechuza de Minerva - la filosofía - no inicia su vuelo hasta el atardecer, post-factum (Hegel, 1940 [1820]:45), y lo mismo le pasa al pensamiento crítico en general. Para Hegel era una prueba de sabiduría. Hoy, a mi juicio, indica que el pensamiento llega cuando los hechos han estallado ya, como lo demuestra tristemente Sopa de Wuhan (Agamben e.a., 2020) o como se lo reprochó Jens Anderman a los Estudios Culturales (Andermann, 2017). Se trata siempre de una imposibilidad de prever las causalidades múltiples que desde la ciencia y el arte, en cambio, fueron imaginadas con soltura, porque trabajan con hipótesis. Así, cuando la física era la newtoniana, un fenómeno era considerado ordenado cuando sus movimientos podían explicarse en un esquema de causa y efectos, y ese esquema se podía representar en una ecuación diferencial. En filosofía, esa causalidad es la base de la dialéctica hegeliana: tesis, antítesis y síntesis. Dos siglos antes, sin embargo, Shakespeare había demostrado que la oposición entre el conflicto familiar y el amor no era la causa de la tragedia, sino un accidente estúpido, la carta perdida de Julieta. Fue un desastre, palabra que Heilman explica poética y etimológicamente como un revés de las estrellas (Heilman, 1968:22). Puede continuarse la coincidencia formal entre la entropía, segunda ley de la termodinámica - descubierta por Rudolf Clausius en 1865 - que introdujo un tiempo pesimista de decadencia y disolución en el universo eterno newtoniano, y la dialéctica negativa de Adorno, que tiene como adversario principal el principio de síntesis o de identidad, responsable de Auschwitz (Adorno, 2005 [1966]). El postestructuralismo francés, traducido por la academia norteamericana, completó la tarea.

Ahora bien, la teoría de la turbulencia o de la totalidad, o del caos, le opone a la entropía las iteraciones o intermitencias, apariciones imprevistas de nuevos órdenes en medio de fluctuaciones aleatorias. Se puede situar el nacimiento de la teoría en 1963, cuando Edward Lorenz (1963) publicó sus investigaciones sobre el comportamiento de los sistemas no lineales, posibles gracias a los primeros computadores que incluían más de tres decimales. Sus descubrimientos confirmaron las hipótesis de Poincaré a fines del siglo XIX, pero también pasaron inadvertidos hasta la década de 1970. En 1979 Ilya Prigogine descubrió las estructuras disipativas (Prigogine y Stenghers, 2004 [1979]:181), momentos de autoorganización en los que emergen sistemas nuevos que aprovechan la entropía. Este descubrimiento fue rápidamente valorado, no solo por la física, sino también por la química, demografía, y ecología: pero mucho antes, casi simultáneamente con Lorenz, un pintor argentino, Luis Felipe Noé, había explicado su trabajo en términos de la - más que incipiente - teoría del caos (Noé, 1965).

El cambio es causado por un elemento incontado en un sistema que siempre es invisible hasta que provoca un tsunami o una revolución: no se trata de una intensidad que desborda, sino de una ruptura radical. ${ }^{4} \mathrm{~A}$ diferencia de la concepción bíblica del orden surgiendo del caos, la teoría de la totalidad - o de las catástrofes - plantea una dinámica entre ambos: el caos surge del orden y a su vez genera formas. Las reflexiones sobre el realismo que desarrollo aquí son las de un artista - un dramaturgo - Rafael Spregelburd, quien, como Noé, encontró en la teoría del caos las imágenes que generaron sus obras: 
Si uno mira un hormiguero, por ejemplo, al principio ve solo hormigas que van en todas direcciones, durante un tiempo lo único que uno ve es caos. Pero si lo mira más tiempo, más tiempo, más tiempo, empieza a comprender que las hormigas que llevan alimento van en una dirección, que las que no llevan alimento van en otra dirección. Es decir que aquello que al principio no tenía reglas, solamente por la mera observación, empieza a generar reglas. No hay ninguna forma caótica que no genere, dentro suyo, reglas de orden (Spregelburd en Théâtre Varia, 2017).

El mecanismo entre el orden y el caos es la retroalimentación: el efecto de las variaciones mínimas del orden - amplificación y ramificación — que se multiplican repetidamente. El término también es utilizado en acústica: es la «realimentación positiva que entra en acción cuando el micrófono está demasiado cerca del parlante [...] un proceso de amplificación donde el producto de una etapa se transforma en alimento de otra» (Spregelburd, 2001:192). Es la conciencia de la lateralidad, niveles que coexisten y que provocan efectos imprevisibles: explosiones, fisuras súbitas en materiales, skyquakes. Hubo elementos que provocaron la hecatombe, sin duda, pero fueron múltiples y solo pueden rastrearse retrospectivamente: eso implica cuestionar la naturaleza del tiempo. Frente a la catástrofe, no hay nada que hacer, «es imposible explicarla, salvo con un razonamiento que se saltee las causas para llegar a los efectos. Y esta es la definición más atinada de catástrofe» (Spregelburd, 2010: 177).

«¿Qué es real?» les preguntaron en 2002 los organizadores del Wiener Festwochen - Festival de Viena - a Rafael Spregelburd y a otros cuatro dramaturgos de «países en crisis terminales» (Spregelburd, 2010:167). Crisis, en latín, refiere a una mutación grave que sobreviene en una enfermedad, y a un momento decisivo en un asunto importante. En griego $\chi$ píıৎ es decisión, derivada a su vez de $\chi$ pivelv, separar, decidir o juzgar. La mutación no refiere solo a un cuerpo biológico, sino también a un cuerpo político (Corominas, 1976:944-955). Es así muy pertinente que los vieneses les pregunten por lo real a artistas de países que afrontan cambios radicales,

ya que la política es - justamente - la modificación de lo real, pero lo hemos olvidado, porque quienes la ejercen como profesión, los políticos, ya se han adaptado a un trabajo que ha dejado de ser la modificación de lo real para pasar a ser simplemente la administración de lo que hay, de lo posible real (Spregelburd, 2010:169). ${ }^{5}$

Spregelburd coincide aquí con las definiciones de la política y la policía de Rancière (2015:36): el poder de crear un orden, por un lado, y la organización, administración y control de ese orden, por el otro.

Lo que administra la política es lo que hay: «diríamos entonces con dolor, que hoy la política quedó reducida básicamente a la administración pública de las imágenes» (Spregelburd, 2010:169). Spregelburd les dio a los vieneses, para explicarles la crisis, una imagen de vacas faenadas por gente hambrienta en la autorruta Buenos Aires-Rosario, en 2002, que fue una conmoción mediática, pero que fue cuestionada casi inmediatamente: los rumores suponían una puesta en escena orquestada por diferentes políticos. De hecho, la anécdota reapareció varias veces en otros momentos. Se instaló así la incertidumbre sobre lo real - una construcción entre otras - y luego su utilidad, su interpretación. Pero la realidad, dice Spregelburd citando a Del Estal, es

la resistencia de las cosas a todo orden simbólico (...) Lo real (atención, señores austríacos, que acá cumplo con el pedido) sería entonces para mí la parte del acontecimiento que el lenguaje no puede capturar. (...) cuando [la realidad] aparece, lo hace como catástrofe, un puro efecto que entierra sus causas (Spregelburd, 2010:170-171)

Rancière, Badiou y Ferraris son filósofos que reivindicaron - en el caso de Badiou, en diálogo explícito con el teatro, la poesía y las matemáticas - la emergencia del cambio. No fueron escuchados, sin embargo, por el mainstream de la finitud posmoderna: los artistas, desde Shakespeare hasta Noé, tampoco hicieron mucha mella en la lechuza de Minerva. Ese «real» que define 
Spregelburd, usando el mismo término de Badiou, acontecimiento, no es representable: «no se puede competir con políticos y medios, campeones en construir realidades y en fabricar imágenes» (Spregelburd, 2010:170-171). Sí se puede usar esas imágenes, en cambio, mostrando que son un semblante y hacerlas vacilar, no hacia la ficción, como en la anécdota de las vacas, sino por el contrario, hacia lo real: intentar «una forma muy curiosa de realismo, que no es parecerse a la realidad (...) sino hacer cómplice al espectador de que está frente a una actuación, pese a que esta esté atravesada por estados de verdad. Y que eso es lo real» (170-171).

\section{Pongamos por caso}

En el programa del FILBA (Festival Internacional de Literatura de Buenos Aires) de 2020 figura, bajo la rúbrica «Performance», Pongamos por Caso (Spregelburd y Moguillansky, 2020). En la obra dialogan por zoom varios traductores ${ }^{6} \mathrm{y}$ hay fábulas en distintos idiomas en voz off que se superponen a veces a los diálogos y cuya traducción al castellano desfila en uno de los cuadritos del zoom.7 El espectador comprende rápidamente que no está frente a una performance, aunque la rúbrica del FILBA, el formato - los cuadritos del zoom - y el diálogo entre Spregelburd y los traductores lo sugieran. La transmisión no es en directo y hay, ostensiblemente, montaje.

Pongamos por caso aparece como performance porque debía serlo si era presencial. Cuando ellos (FILBA) me llamaron fue antes de que surgiera la pandemia y me habían contratado para hacer una performance. Los traductores iban a estar en Buenos Aires, invitados para otras actividades del festival. Lo que habíamos pactado es que íbamos a hacer algo que se pudiera ensayar en una semana y que se hiciera en vivo. Era, de verdad, un concurso de preguntas y respuestas con los traductores tratando de proponer soluciones en vivo. Era perfomático, no iba a haber texto escrito y yo me comprometí a hacerlo. Cuando después devino no presencial yo les dije que eso del concurso no tenía ninguna gracia, porque estando grabado y filmado no hay ninguna adrenalina. (...) Ellos ya tenían la partida de dinero asignada, me volvieron a contratar y me dijeron qué otra cosa podés hacer con ellos. Les dije, nada: las charlas las grabamos y ficcionalizamos lo que se pueda, o sea, por partes quizás sí haya textos que podamos escribir. Me dieron el OK y empezamos a laburar. Cuando empecé a trabajar con ellos yo no tenía ningún texto escrito, les dije: me gustaría llegar a una parte de esto escrita por mí y otra parte que sean los aportes de ustedes. Así que siguió contando como performance, porque para ellos, para FILBA, mantiene el espíritu del contrato, que es que los traductores responden espontáneamente sin la presencia de un texto escrito. (Spregelburd en Rodríguez Carranza, 2021)

«Es muy difícil entender qué es» - agrega Spregelburd- «por momentos es un documental, por momentos es una entrevista, cuasi académica, poética y lo que no es seguramente es una obra de teatro (...) es lo más teatral que se podía lograr en esas condiciones» (Spregelburd en Rodríguez Carranza, 2021). Lo que sucede, a mi juicio, es que es todo eso simultáneamente. Es sin duda un documental, que puede describirse con las características del «giro neo-documental» de Jameson; un «nuevo concepto de lo real tanto hallado como producido por el film (...) no una función de cualquier verdad histórica que puede oponerse a lo ficticio» (Jameson, 1992:190). También puede considerarse que es una de las performances delegadas que le interesan a Bishop, aquellas «en las que el artista no solo registra sino también concibe toda la situación que se está filmando y en que los performers se interpretan a sí mismos» (Bishop, 2010-2011). En Pongamos por caso está, efectivamente, la performance de los traductores, pero también hay textos escritos por Spregelburd, subtítulos que no traducen lo que dicen los participantes en el zoom, sino lo que dicen las voces, etc. Además, no hay en la obra ninguna duda, ni límite borrado, entre ficción y documental o performance, porque están perfectamente delimitados: es más, hay una clara exhibición y confrontación de las diferencias. 
Después de una introducción se suceden seis capítulos y, en simultáneo, cinco fábulas en voz off y dos videos de youtube. Pongamos por caso dura dos horas y cincuenta y un minutos, y es imposible describir su dinámica, que es vertiginosa: transcribir un fragmento - cinco minutos - es la única manera de poder presentarla y de señalar algunas de las innumerables resonancias. La obra se inicia con los sollozos de un hombre joven en primer plano diciendo «yo no soy el monstruo que ustedes creen» - antes del título y los nombres de los participantes - en orden alfabético. Lo que sigue tiene lugar, según un letrero, «dos horas antes». Una voz en off - la de Svenja Becker - narra en alemán una fábula sobre Balder, favorito de los dioses. Aparece luego el damero del zoom, y mientras continúan la voz y la traducción - con fondo negro en uno de los cuadritos - Spregelburd saluda a los participantes. Sus palabras son a veces inaudibles, porque la voz tiene más volumen:

Claro, los dioses nórdicos, con el cerebro lleno de nieve, no sabían que en el misterio de todas las palabras, como «inmortal»o «múerdago», o «mundo», opera una maquinaria invisible. (Spregelburd y Moguillansky, 2020) ${ }^{8}$

«Les cuento» - está diciendo Spregelburd cuando podemos oírlo y su imagen pasa a primer plano como sucede en los zoom al usar el micrófono - «lo que les anticipé: esto es un evento bastante excepcional. Nosotros pensábamos hacer de esto una performance...» Sus palabras son silenciadas por la voz en alemán que se impone, mientras la traducción va en subtítulos: «Los pequeños "Takers" (Nehmer) propulsan las maquinitas que forjan los sonidos y activan las chispas de la lengua».

En ese momento, aparecen todos los cuadritos del damero, pero en ellos se dislocan las imágenes, con la cabeza de un traductor, el torso de otro y los pies de un tercero, y terminan apareciendo las computadoras respectivas. Mientras tanto, siguen la voz y los subtítulos, narrando que la reina Frigg proclamó un edicto para salvar a su hijo Balder, el bello, el favorito de los dioses. Sentándose frente a sus pantallas reaparecen los participantes en sus cuadritos, y Spregelburd les explica que fueron convocados porque son traductores del castellano a diversas lenguas y algunos, como él mismo y Ariel Dilon, ${ }^{9}$ de otras lenguas al castellano. Cuando hablan Spregelburd y Dilon pasan a primer plano: en ese momento la traducción de la fábula no va en cuadrito aparte, sino como zócalo, incongruente con lo que dicen:

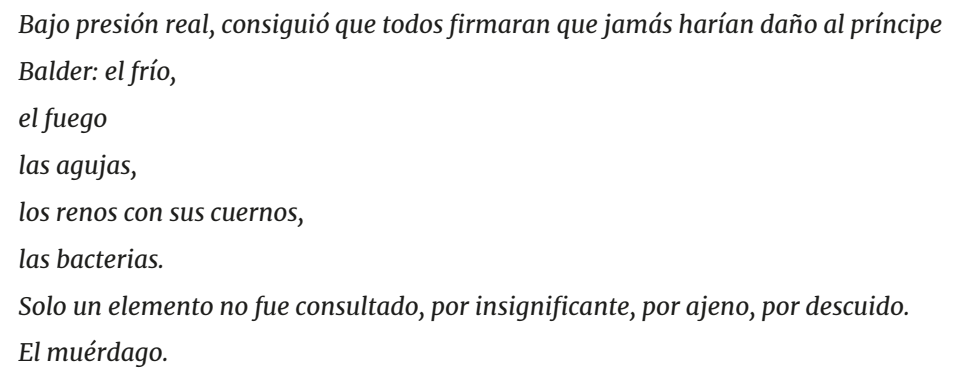

En la pantalla aparecen en blanco sobre negro las palabras «Capítulo I. EL MUÉRDAGO» y luego el damero. Spregelburd: «Por eso, en vez de hablar en términos técnicos, porque la situación no es simétrica, vamos a hablar en otros términos». Javier (el hombre joven del principio): «¿en qué otros términos?» La voz: «nadie lo consultó, nadie reparó en él.» Spregelburd: «ehh...en otros...». La voz: «Nadie le dijo nada». Javier: «Pero pará, perdón, ¿esto requiere más tiempo? ¿Nos vamos a tener que quedar más tiempo acá?» La voz: «y la planta no firmó el pacto. Era demasiado joven para firmar nada». Spregelburd: «no sé, igual lo vamos a editar. Se pueden desconectar en cualquier momento y de todos modos no están obligados a contestar las preguntas ni a hacer nada que no quieran.» La voz: «Después Loki hizo lo suyo. Loki, que odiaba a todos». Javier: «Igual yo me quedo, hasta que no sienta la presión de que me tengo que ir...» La voz: «puso una flecha de muérdago en el arco de Hodur, el tonto hermano ciego y sin gracia» Spregelburd: «bueno, no, presión no... ehhh (a 
Plantte): ¿qué tal, Rodo, cómo estás?» La voz: «Y cuando todos los dioses jugaban a herir a Balder en vano con sus golpes, Hodur lanzó la flecha que lo mató para siempre».

Hay dos bandas visuales, el damero del zoom con los participantes en sus cuadritos y la traducción del alemán en cuadrito o zócalo, y tres sonoras, música, fábula en voz off y diálogos de Spregelburd con los traductores. Como señalé más arriba, no coinciden siempre, es como si las bandas se hubieran desfasado en el montaje: se yuxtapone, por ejemplo, la misma voz, la de Becker, en dos bandas diferentes, en la entrevista y leyendo la fábula de Balder, o su imagen silenciosa y la traducción en zócalo de su voz en off. En pocos minutos, sin embargo, queda claro que esos procedimientos técnicos provocan una fricción entre los participantes. Los ecos o resonancias son constantes, como la presión de la reina en la fábula y la declaración de Javier diciendo que se quedará hasta que sienta la presión de tener que irse, o entre el muérdago - en quien nadie reparaba - y Javier, ignorado en los saludos. Hay un momento de flexión en el capítulo, cuando Spregelburd afirma «esto es una pieza de ficción» y se dirige a Cherubini diciendo que en italiano no existe la palabra, porque literalmente significa mentira; en guaraní, según Rodolfo, ficción es juego, reflejo, simulación. Javier interrumpe a este último preguntándole si da clases de danza, y Rodolfo responde sorprendido que da clases pero son de la universidad. Javier: «Pero, ¿son clases?» Rodolfo: «sí, pero para la gente de la universidad». Javier: «Bueno, sigan, no pregunté nada» (...). Riendo: «acá parece que para seguir clases de danza hay que ir a la universidad» (...) «si vamos a hacernos los boludos con cosas reales sigamos al servicio de cosas irreales». Ignorando el malentendido, Spregelburd continúa:

Pongamos por caso que esto es ficción. Vamos a tratar de hacer algunos ejercicios imposibles, la idea era hacerlo en vivo, y con premios, una licuadora, una tostadora que vamos a dejar para el final. Traducir en vivo, traducir contra el reloj, ejercicios espirituales de algo que yo creo bastante imposible, como si el traductor fuera un intérprete cultural, en problemas ante cierta urgencia. Como si el traductor fuera un traductor instantáneo de palabras, adaptador de cultura, enchufe, descubridor de connotaciones, un explicador colonialista, un apropiador de lo ajeno.

Suponer que las entrevistas sean ficcionales es, como dice Javier, seguir «al servicio de cosas irreales»: no es una ficción realista, sino una realidad que juega a ser ficción. Los ejercicios propuestos son el programa de los capítulos siguientes, y Javier interviene: «¿Hay que votar?», atrayendo por fin la atención de Spregelburd, quien le pregunta cómo llegó ahí y de qué idiomas traduce. La respuesta es que fue invitado - como todos - y que traduce a partir de las lenguas comunes, inglés, alemán o chino. Traduce para empresas, instrucciones para diversos aparatos y lo hace con Google (plataforma virtual). A partir de ese momento es el centro de atención, y los malentendidos humorísticos abundan: «¿no tenés formación en ninguna lengua?» «Sí, ... soy trabajador sexual». Insiste en que trabaja para generar placer y Ariel ríe «el placer del manual». Javier ofrece sus servicios: «traducciones sí podríamos utilizar», contesta Spregelburd y Manuela admite que podrían tercerizar. «Yo necesito un clon», exclama Ian.

«Vamos a empezar, si les parece» declara Spregelburd y aparece el título del capítulo siguiente que retoma la palabra lengua: «LENGUA: ¡HABLA!». No está Javier. Los temas que se enganchan unos con otros son la diferencia entre oralidad y escritura, la dificultad de los dialectos, los tabúes, la distribución imperialista de la cultura, las connotaciones sociales de los acentos y dialectos, el orgullo identitario: gran parte del programa anunciado por el entrevistador. La fábula es la de Seth, quien consiguió la llave para rescatar a su amada humana de la muerte pero luego les dio a los hombres infinitas palabras, menos la que nombra el sitio donde está la llave. ${ }^{10}$ Spregelburd piensa en la lengua como la estabilización de una serie de cuerpos, y sigue un monólogo de Ariel sobre la lengua como órgano del placer - palabra en la que resuena el discurso de Javier del primer acto - encarnada, viva: la escritura es prótesis y no hay lengua común. Y agrega «un gesto que active las mismas emociones que adivino, que el gesto del otro genera en el otro». Está claramente leyendo un ensayo estructurado por escrito, que parece resonar en la fábula y viceversa: 
los hombres buscan nombrar el lugar de la llave «en los intervalos de la música, en los gestos de las manos en el baile, en el sonido de las palabras amontonadas, en las rimas». Manuela compara al traductor con un actor que busca en un lugar en su cuerpo, el gesto para llegar a esa emoción es el suyo. Y Ariel agrega que es un intérprete, como un músico, y que el modo de transmisión de la lengua es imitación. «Imitamos el gesto físico del aparato clonador del otro (...) lo que recibimos es el sonido, no el manual de uso del aparato clonador del otro». Las palabras son las del final del primer acto - manual de uso, clon -, y para acentuar la resonancia Spregelburd exclama incongruentemente en este contexto, pero remitiendo a la segunda - o primera - profesión de Javier: «bueno, la verdad entonces es que mejor es la prostitución».

Se pasa a los insultos, y después de un título - «Más allá del inclusivo» - a una entrevista individual con Manuela Cherubini sobre la innumerable cantidad de palabras y expresiones en italiano que son normales en masculino, pero que en femenino refieren a una prostituta - miniotta - lazo con lo anterior. La voz de Spregelburd narra en esperanto la fábula de un joven que, durante una peste medieval, cantó una balada de trovadores ingleses en su ventana, que fue retomada por miles de otros. Al terminar la peste, se le adjudicó la redención a la balada inglesa ecuménica (y a la persecución a los judíos). Este es el lazo con el capítulo tercero, que lleva un nombre que cuesta reconocer como sinónimo del título de la obra.

Supón fue una iniciativa de un grupo de personajes mediáticos argentinos durante la pandemia, quienes, imitando otros intentos internacionales, decidieron cantar Imagine, de John Lennon, cada cual en su casa, y luego montaron la canción (Tamara Bella, coord. 2020). Es la balada del trovador inglés del capítulo anterior, que cada uno cantaba en su ventana, sin poder reunirse por la peste. Los otros casos de Imagine cantada de esta manera que pueden encontrarse en YouTube son más o menos logrados o ridículos, pero lo que hace a Supón único es, para no hablar de las notas desafinadas, la traducción espantosa de Google, que, además, fue tijereteada sin ton ni son para adaptarse a las necesidades rítmicas de la melodía. Así y todo, tuvo mucho éxito en internet. El tema del capítulo es el error que hace que aparezca el objeto. Es el caso de la corrección efectuada a veces por los traductores sobre los originales, y eso lleva a la adaptación cultural en el capítulo 4, «TODOS INDIOS».

En el capítulo 5 - «El águila imperial» - Ian cuenta que está traduciendo La Refalosa, de Ascasubi, de una violencia tal que es extraña para sus lectores ingleses. Los temas que siguen son la injerencia de los traductores, su autonomía y luego cómo eligen lo que traducen: «se busca lo propio en lo ajeno», dice Spregelburd. Manuela habla de «apropiarse» el texto. Hay algo innombrable: Ariel reivindica algo universal, Ian de un hilo de contacto. «Algo que me habla a mí», agrega Manuela. La voz - con acento sureño - de Frances Riddle lee en off un texto sobre De la tierra a la luna que destaca que Jules Verne eligió Florida y no Texas para lanzar un proyectil a la luna: y es también Florida donde se instaló Cabo Cañaveral. Los tejanos quedaron para siempre «Unchosen», no elegidos.

El capítulo final - «EL OTRO LADO» - es el ejercicio de traducción simultánea, por zoom y performática - aunque montado luego - que, según Spregelburd, fue la idea original de la obra. El desafío es un huayno peruano, La Tetita, de Wendy Silca, una niña de 7 años, cuyo éxito radicó probablemente en el efecto casi pornográfico de la inocencia de la niña yuxtapuesta a la presencia de adultos en la edición de YouTube. En los otros cuadritos los traductores intentan infructuosamente conseguir equivalentes, no solo de la palabra «tetita» - imposible en inglés para Frances - sino de ese efecto ambiguo.

\section{Unchosen}

Los tres materiales de la obra - el diálogo entre Spregelburd y los traductores, las fábulas en voz off y Javier - producen efectos diferentes, como en una partida de ajedrez acelerada, y las resonancias circulan como descargas eléctricas en cadena. Así, la estructura parece simple: el grupo de profesionales ocupa el lugar diseñado por el entrevistador, 
y el zoom es una de performance delegada. Las dos otras presencias interrumpen: la voz de las fábulas y la música que la acompaña insertan un tiempo mítico, y las intervenciones extemporáneas de Javier parecen estar ahí para molestar a los demás.

De hecho, la situación es la inversa. Las fábulas y las intromisiones de Javier han sido redactadas por Spregelburd, son el orden previo, aunque algunos textos se hayan escrito paralelamente a las reuniones de zoom. Los traductores desordenan, atractores internos o externos, como en la teoría del caos: van enredando los diálogos en telarañas y son arrastrados por las resonancias de la lengua: los takers nunca encontrarán la palabra justa. Están en compartimientos separados, como los replicadores de la balada inglesa, solos con sus imposibilidades y la escena final - el concurso - es la catástrofe.

Si se observa detenidamente el caos, sin embargo, como el del hormiguero, «más tiempo, más tiempo, más tiempo» (Spregelburd en Théâtre Varia, 2017), empieza a generar reglas. La cacofonía del capítulo final parece una resonancia de Supón. Es lo que fue el tema de cada uno de los capítulos lo que interpela a los traductores a atrapar en la traducción lo que los atrae en lo ajeno. Es lo real, que no es innombrado, no es inefable sino todo lo contrario: vive en las palabras que los desafían a encontrar equivalencias imposibles. En la última de las fábulas, Irupé, analista de sistemas de Panambiretá, en Asunción, ${ }^{11}$ se dedicó - durante una pandemia, en 2020 - a clasificar los comentarios críticos sobre la obra de su padre, artista plástico fallecido. Imaginó así un código de combinaciones posibles de los contenidos de los comentarios, pero a la larga, y a diferencia del «Mapa del Imperio, que tenía el tamaño del Imperio y coincidía puntualmente con él» (Borges, 1974: 847), Irupé llegó a una categoría contradictoria, posible en la lógica del código pero en la que ninguno de los textos podía alojarse: era suplementaria e intransitiva, no tenía objeto fuera de sí misma.

Queda mucho por pensar en Pongamos por caso; el llanto de Javier, por ejemplo, una introducción que se anuncia como posterior a todo lo que sucede. El traductor de Google es el único que nunca había dudado de la correspondencia entre las palabras y parecía haber quedado fuera de la catástrofe. ¿La escena es efecto imprevisto, cambio, réquiem o redención? Está fuera del alcance, en todo caso, de la lechuza de Minerva, que no entiende las hipótesis, pero una vez más, apelar a discursos de otros ángulos puede ser útil. Las lágrimas en el melodrama - que nunca está lejos en el teatro de Spregelburd - pueden ser causadas por varios mecanismos, pero el más frecuente es la imposibilidad de intervenir. El espectador no puede hacer nada frente al destino irreversible de los personajes: se ha construido para él un lugar en el que es llevado a desear lo imposible (Neale, 1986:12). Quizás sea el caso de Javier. Y el nuestro.

\section{Referencias}

Adorno, Theodor W. (2005). Dialéctica negativa. La jerga de la autenticidad. Obra Completa, Vol. 6. Akal (1966).

Andermann, Jens (2017). Para una hermenéutica de la enemistad: los estudios culturales latinoamericanos y el nuevo fascismo. Cuadernos de Literatura, 21(41), 79-89.

Badiou, Alain (2004). La Ética. Ensayo sobre la conciencia del mal (Traducción al español: Raúl J. Cerdeiras. Revisión de traducción: Álvaro Uribe). Editorial Herder (2003).

Badiou, Alain (2008). Lógicas de los mundos. El Ser y el Acontecimiento 2 (Traducción al español: María del Carmen Rodríguez. Revisión técnica: Raúl Cerdeiras). Manantial (2006).

Bella, Tamara [TamiBellaTB] (2020). "SUPÓN 2020" LA VERSIÓN ARGENTINA DE IMAGINE [Archivo de Vídeo]. Youtube. https://www.youtube.com/ watch?v=kA60510-k3w 
Bishop, Claire (2017). Performance delegada: subcontratar la autenticidad. Otra Parte (22). https://www.revistaotraparteimpresa.tk/n\%C2\%BA22-verano-2010-2011/cuaderno-performance-delegada-subcontratar-la-autenticidad

Boletín 12 (2020). Cetycli (Centro de Estudios de Teoría y Crítica Literaria) Rosario. Universidad Nacional de Rosario.

Borges, Jorge Luis (1974). Obras completas 1923-1972. (Dirección y realización: Carlos V. Frías). Emecé Editores.

Contreras, Sandra (2007). Narrativa argentina del presente. Katatay, revista crítica de literatura latinoamericana (5), 6-9.

Contreras, Sandra (2018). En torno al realismo y otros ensayos. Nube Negra Ediciones.

Corominas, Joan (1976). Diccionario crítico etimológico de la lengua castellana, vol. I. Gredos.

Escobar, Ticio (2004). El arte fuera de sí (27 fragmentos sobre la paradoja de la representación y una pregunta sobre el tema del aura). En El arte fuera de sí (pp.141-156). FONDEC/CAV Museo del Barro, 2004.

Ferraris, Maurizio (2012). Manifiesto del Nuevo Realismo (Traducción al español: José Blanco Jiménez. Colaboración: Alessandro Santoni. Revisión y edición final: Manuel Loyola). Ariadna Ediciones.

Foster, Hal (2001). El retorno de lo real. La vanguardia a finales de siglo (Traducción al español: Alfedo Brotons Muñoz). Akal (1996).

Giorgio, Agamben e.a. (2020). Sopa de Wuhan. ASPO. http://iips.usac.edu. gt/wp-content/uploads/2020/03/Sopade-Wuhan-ASPO.pdf

Gramuglio, María Teresa (1986). El lugar de Saer. En Juan José Saer por Juan José Saer (pp. 325-237). Editorial Celtia. También en Crítica Cultural 5(2). http://www.portaldeperiodicos.unisul.br/index.php/Critica_Cultural/ article/view/695/650

Gramuglio, Maria Teresa (1990). Genealogía de lo nuevo. Punto de Vista, (39), pp. 5-10. También en https://ahira.com.ar/ejemplares/39-6/

Gramuglio, María Teresa (2002a). Políticas del decir y formas de la ficción. Novelas de la dictadura militar. Punto de vista (74), 9-14.

Gramuglio, María Teresa (2002b). El realismo y sus destiempos en la literatura argentina. En Gramuglio, María Teresa (Dir.) El imperio realista (pp.15-28). Emecé.

Hegel, Georg Wilhem Friedrich (1940). Préface. Principes de la philosophie du droit (Traduit de l'allemand par André Kaan et préfacé par Jean Hyppolite). NRF/Gallimard (1820), 29-45.

Heilman, Robert Bechtold (1968). Tragedy and Melodrama. Versions of Experience. University of Washington Press.

Jameson, Frederic (1992). Signatures of the Visible. Routledge.

Laddaga, Reinaldo (2007). Espectáculos de realidad. Ensayo sobre la literatura latinoamericana de las últimas dos décadas. Beatriz Viterbo.

Ludmer, Josefina (2010). Aquí América Latina. Una especulación. Eterna Cadencia Editora.

Lorenz, Edward N. (1963). Deterministic nonperiodic flow. Journal of the Atmospheric Sciences (20), 130-141.

Neale, Stephen (1986). Melodrama and tears. Screen (27), 6-22.

Noé, Luis Felipe (1965). Antiestética. Ediciones de La Flor. 
Prigogine, Ilya y Stenghers, Isabelle (2004). La nueva alianza. Metamorfosis de la ciencia. Alianza Editorial (1979).

Rancière, Jacques (1996). El Desacuerdo. Política y filosofía. Nueva Visión (1995).

Rancière, Jacques (2003). S'il y a de l'irreprésentable. En Le destin des images (pp. 125-152). La Fabrique Éditions.

Rancière, Jacques (2008). Les paradoxes de l'art politique. En Le spectateur émancipé (pp. 56-92). La Fabrique.

Rancière, Jacques (2010). Las paradojas del arte político. En El espectador emancipado (pp. 55-85) (Traducción Ariel Dilon. Revisión de Javier Bassas Vila). Eliago Ediciones (2008).

Rancière, Jacques (2015). Ten Theses on Politics. En Corvoran, Steven (ed.). Dissensus. On Politics and Aesthetics (pp. 25-52). Bloomsbury.

Rodríguez Carranza, Luz (2016). Resonancias y ocupación. La cuestión del «arte fuera de sí» en Spam, de Rafael Spregelburd y Federico Zypce. Cuadernos de Literatura, 20(40), 131-154.

Rodríguez Carranza, Luz (2019). Hacia un sujeto intransitivo. Philip Seymour Hoffman, par exemple, la obra belga de Rafael Spregelburd (2017). El Taco en la Brea. 1(9), 77-85. https://doi.org/10.14409/tb.v1i9.8191

Rodríguez Carranza, Luz. Entrevista con Rafael Spregelburd. Audiowsp 1207-2021

Silva Hurtado, Nadia (2013). Rafael Spregelburd y el teatro traducido en América Latina. Mutatis Mutandi, 6(2), 561-566.

Spregelburd, Rafael (2001). Fractal, una especulación científica. Libros del Rojas,

Spregelburd, Rafael (2010). Tres apuntes sobre dramaturgia. En Cosentino, Olga (ed.). La puesta en escena en el teatro argentino del bicentenario (pp. 165-192). Fondo Nacional de las Artes.

Spregelburd, Rafael [Théâtre Varia] (6 de agosto de 2017). Interview de Rafael Spregelburd - Théâtre Varia. [Archivo de Video]. https://www.youtube.com/watch?v=1G7i1zucS20.

Spregelburd, Rafael y Alejo Moguillansky [Filba Literatura]. (2020). Pongamos por caso. [Archivo de Video]. https://www.youtube.com/ watch?v=UK9J2gBdpEg\&t $=1361 \mathrm{~s}$

\section{Notas}

1. Las jornadas tuvieron lugar el 9 y el 10 de diciembre de 2005 y la mayoría de las ponencias fueron publicadas en Boletín del Centro de Estudios de Crítica Literaria (2005).

2. Contreras (2018:9) cita en esta frase dos textos de Gramuglio (1986 y 1990) libremente, sin precisión de página.

3. Todas las traducciones y transcripciones son mías, salvo indicación contraria. Contreras (2018:21) cita en extracto este mismo párrafo de Rancière por la traducción de Ariel Dilon (Rancière, 2010:78).

4. Alain Badiou explica las diferencias entre su concepción de acontecimiento - ruptura - y la de Deleuze - intensidad - en «El acontecimiento según Deleuze», en Badiou (2008 [2006]:423-430).

5. Las itálicas en todas las citas de Spregelburd 2010 son suyas.

6. Los traductores son Rafael Spregelburd (entrevistador), Ian Barnett, Svenja Becker, Manuela Cherubini, Ariel Dilon, Rodolfo Prantte y Frances Riddle. También participa un «traductor» que usa Google, el actor Javier Mauro.

7. La traducción no solo es una actividad constante de Spregelburd - cf., entre otros, Silva Hurtado (2014 [2013]) - sino que es uno de los resortes principales de sus obras: los malentendidos, la producción deliberada de la sensación de que, aunque 
todo esté ahí y se repita en infinitas variantes, siempre hay pérdidas y equivocaciones. Hay obras que tratan exclusivamente de la traducción: antes de Pongamos por caso (2020) ya está - entre otras obras - en el primer capítulo de Bizarra (2003), en Spam (2012), en Furia Avícola (2014) y en dos módulos de El Fin de Europa (2017).

8. Todas las citas en adelante corresponden a Spregelburd y Moguillansky (2020). La transcripción es mía. He optado por las itálicas para indicar los textos en voz off porque es lo que acostumbra hacer Spregelburd en sus textos publicados.

9. Es una resonancia en mi propio texto que Ariel Dilon sea también el traductor de la edición de Rancière que utiliza Sandra Contreras.

10. La llave de la puerta que separa a los vivos de los muertos ya está en El Pánico (2003), de Spregelburd.

11. El barrio de Irupé lleva un nombre que es un guiño a la teoría del caos: Panambretá, hogar o tierra de la mariposa en guaraní. 